\title{
DISTINÇÃO DE CULTIVARES DE FEIJOEIRO (Phaseolus vulgaris L.) PELO MÉTODO DA CRISTALIZAÇÃO SENSITIVA *
}

\author{
IBRAHIMI OCTAVIO ABRAHÃo **
}

\begin{abstract}
RESUMO
Estuda-se a possibilidade de introduzir cultivares de plantas como modificador do modelo de cristalização do clorcto de cobre. Os modelos de cristalização de raízes, caules, folhas, flores e sementes de 3 cultivares de feijoeiro e para diferentes idades de plantas de solução nutritiva foram obtidos, principalmente na concentração $0,05: 0,5$, com 5 repetições. A comparação dos modelos revela que a sensibilidade do método é suficiente para que possa ser empregado na distinção de cultivares da espécie, especialmente através de modelos de cristalização obtidos com extrato de flores.
\end{abstract}

\section{INTRODUÇÃO}

O emprego da cristalogênese do cloreto de cobre na caracterização de extratos aquosos de plantas tem mostrado que as principais causas de variação do modelo de cristalização são: a espécie, o órgão, as concentrações do sal e do extrato, a idade da planta, a hora de coleta e a procedência do material. Nenhuma referência tem sido feita sobre a possibilidade de ser a diferença entre cultivares também uma causa de variação. Neste trabalho, são relatadas as diferenças em modelos de cristalização causadas por 3 cultivares de feijoeiro (Phaseolus vulgaris L.).

\section{REVISÃO DA LITERATURA}

Trabalhos sobre a aplicação da cristalização sensitiva a plantas econômicas são relativamente pouco numeroses. Mencionam-se, aqui, os principais trabalhos que relacionam plantas como causa de variação nos modelos de cristalização do cloreto de cobre.

* Entregue à pulblicação em 25-11-1976

* Departamento de Solos, Geologia e Fertilizantes - ESALQ 
PFEIFFER (1930) mostrou a influência da adubação sobre o modelo de cristalização. Posteriormente, (1940), mostrou que há diferenças significativas entre modelos de plantas sãs e atacadas por fungos. MORRIS e MORRIS (1938, 1939 e 1940) mostraram o efeito específico de sementes de cereais (aveia, trigo e milho), bem como de seus amidos e da presença de pequenas quantidades de proteínas. KRÜGER (1949, 1950) mostrou a influência sobre os modelos de diversas plantas medicinais, bem como da hora de coleta do material. SELAWRY e SELAWRY (1957) mostram, em extratos de ervilhas, que a adubação, mineral ou orgânica, e a procedência de solos argilosos ou arenosos, afetam o modelo de cristalização. ABRAHÃO (1965) mostra o efeito que exercem sobre o modelo de cristalização, os extratos aquosos de orgãos de feijoeiro, de cultivares diferentes, em diferentes estágios de desenvolvimento. E a primeira menção que se faz na literatura sobre a possibilidade de distinção cristalogenética de cultivares de espécies vegetais. Seus resultados são a base do presente trabalho. ABRAHãO (1970) estuda a influência de diferentes concentrações sobre o modelo de cristalização de sementes de café. ABRAHÃO (1971) faz o estudo morfológico da cristalogênese do cloreto de cobre, especificamente para feijoeiro. ABRAHÃO (1971) faz revisão dos resultados alcançados até então com o método. ABRAHÃO (1975) estuda os modelos de cristalização obtidos com sementes de feijoeiro, mencionando alguns caracteres diferenciais entre cultivares.

\section{MATERIAL E MÉTODO}

\section{MATERIAL}

Cultivares - Foram utilizados 3 cultivares de feijoeiro: preto, pintado e roxinho. Os três cultivares exibem diferenças morfológicas nas plantas e se distinguem, especialmente, pelas sementes. As plantas foram obtidas de soluções nutritivas completas.

Câmara de cristalização - Foi empregada câmara de cristalização espetial, de dimensões $1,6 \times 1,6 \times 2,0 \mathrm{~m}$, recomendada por SELAWRY e SELAWRY (1957) e descrita por ABRAHÃO (1965). A câmara possui paredes duplas adiabáticas e dispositivo para manter a temperatura constante até $50^{\circ} \mathrm{C}$. No seu interior, uma mesa de vidro suspensa, de dimensões $0,70 \times 1,50 \times 0,01$, é nivelada com a precisão de $0,02 \mathrm{~mm} / \mathrm{m}$ (nível Wyler) e nela se processa a evaporação das soluções das placas.

Placas de cristalização - Utilizaram-se placas de vidro especialmente montadas para esse fim segundo recomendações de SELAWRY e SELAWRY (1957) e modificações de ABRAHÃO (1965). 
Cloreto de cobre e material fotográfico - Usou-se cloreto de cobre puríssimo p.a. Merck, filmes $25 \mathrm{~mm}$ Kodak Panatomic - X e papel Kodabromide F-4, que permitem grandes ampliações.

\section{MÉTODO}

Técnica de cristalização - A técnica empregada para ambiente de trabalho, velocidade de cristalização, controle de temperatura e umidade, nivelamento, limpeza das placas de cristalização, obtenção do extrato e decurso da cristalização é a que recomendam SELAWRY e SELAWRY (1957), com as modificações sugeridas por ABRAHÃO (1965).

Obtenção das plantas e concentrações - As plantas dos 3 cultivares foram obtidas de solução nutritiva completa. Para roxinho, usaram-se plantas de 19, 25, 33, 45 e 61 dias; para pintado, plantas de 20, 29, 34, 48 e 53 dias; e para preto, plantas de 21, 36 e 60 dias. Em cada cristalização, foram obtidos simultaneamente os modelos de cristalização dos orgãos disponíveis de apenas um cultivar. A não ser nos casos especificamente mencionados, utilizou-se a concentração 0,$05 ; 0,5$ por placa e cada série foi feita com 5 repetições. Todas as placas foram fotografadas em conjunto e em partes de interesse especial.

As observações desse trabalho referem-se ao exame de 23 séries de cristalização para o cultivar roxinho, 21 para o cultivar pintado e 10 para o cultivar preto, num total de 270 placas de cristalização e cerca de 1400 fotografias.

A terminologia empregada é a discutida de maneira específica para feijoeiro (ABRAHÃO, 1971).

\section{RESULTADOS E DISCUSSÃO}

Apresentam-se as comparações entre os modelos de cristalização de raízes, caules, folhas, flores e sementes dos 3 cultivares. Observe-se que, à exceção de sementes, as comparações dizem respeito a séries não simultâneas, como seria desejável. Constituem, todavia, as primeiras informações sobre a possível distinção cristalogênica de cultivares de feijoeiro.

Comparação dos modelos de cristalização de raízes - Para todas as épocas e os 3 cultivares, o modelo para raízes é tipicamente fibroso, de borda vitrificada e sem formas vazias. Esses caracteres permitem que o modelo para esse orgão seja prontamente reconhecido. Entre 
cultivares há uma clara evidência de que, para pintado, o grau de cristalização fibrosa é menor e com menor ocorrência de espessamentos. Para esse cultivar, em plantas mais velhas, chega-se a um modelo em que a diferenciação e o tipo da borda tendem a fugir do quadro geral descrito. Apenas para o cultivar pintado não ocorrem, em nenhuma época, espaços irregulares, comuns nos modelos de roxinho e preto.

Comparação dos modelos de cristalização de caules - O quadro geral para caules é de bom tipo para os 3 cultivares, com uma tendência geral para decrescer em qualidade em plantas mais velhas. $\mathrm{Na}$ concentração de 0,05: 0,75, em plantas de 20 dias, é muito nítida a diferença entre a variedade roxinho, de um lado, e pintado e preto, de outro, embora entre essas últimas também ocorram variações. Em plantas de 50 dias, o cultivar preto exibe muito melhor diferenciação geral. O modelo para roxinho (60 dias) é de muito melhor diferenciação que o de preto (61 dias). Nenhum cultivar é sistematicamente superior aos demais na qualidade de modelos, não havendo caracteres absolutamente seguros para distinção entre cultivares, nesse tipo de comparação.

Comparação dos modelos de cristalização de folhas - O modelo geral de folhas é de tipo satisfatório para os 3 cultivares, com cristalização fibrosa ocasional e nítido decréscimo de deposições em função de idade, pelo que é mais nítido o modelo de plantas novas. A diferenciação da borda também melhora com a idade. Entre plantas novas, o cultivar roxinho tem modelo melhor que os cultivares preto e pintado, este sendo o de pior modelo. Ao nível de 60 dias, há muita semelhança entre os modelos de roxinho e de preto, caracterizados por diferenciação geral de abundante ramificação. Este estágio não foi alcançado para pintado. Essa variedade mostra, com freqüência, desvios de agulhas na cristalização central, não observados para preto e roxinho, mais freqüentes em plantas novas. Cristalizações transversais são comuns, particularmente para pintado. De um modo geral, pode-se dizer que os modelos de preto e roxinho são melhores que o de pintado, sendo provável que este último apresente caracteres diferenciais mais seguros em cristalizações simultâneas.

Comparação dos modelos de cristalização de flores - Os 3 cultivares mostram diferenças sensíveis. O modelo mais típico e característico é o de roxinho. São diferenciais para essa variedade o tipo de cristalização central, espessa, mas sem qualquer tendência para tipo fibroso (Fig. 1) e a presença sistemática de cristalizações transversais (Fig. 2). Para pintado e preto há cristalização fibrosa, a diferenciação geral é pior e não há cristalizações transversais (Figs. 3 e 4). Formas vazias bem caracterizadas são constantes para roxinho e ocasionais para pintado e preto. Para roxinho, a cristalização central e a borda contrastam bem, o que não ocorre para pintado e preto. Entre estes cultivares, podem ser estabelecidas diferenças: melhor tipo de cristalização, de coordenação e de irradiação para preto. 


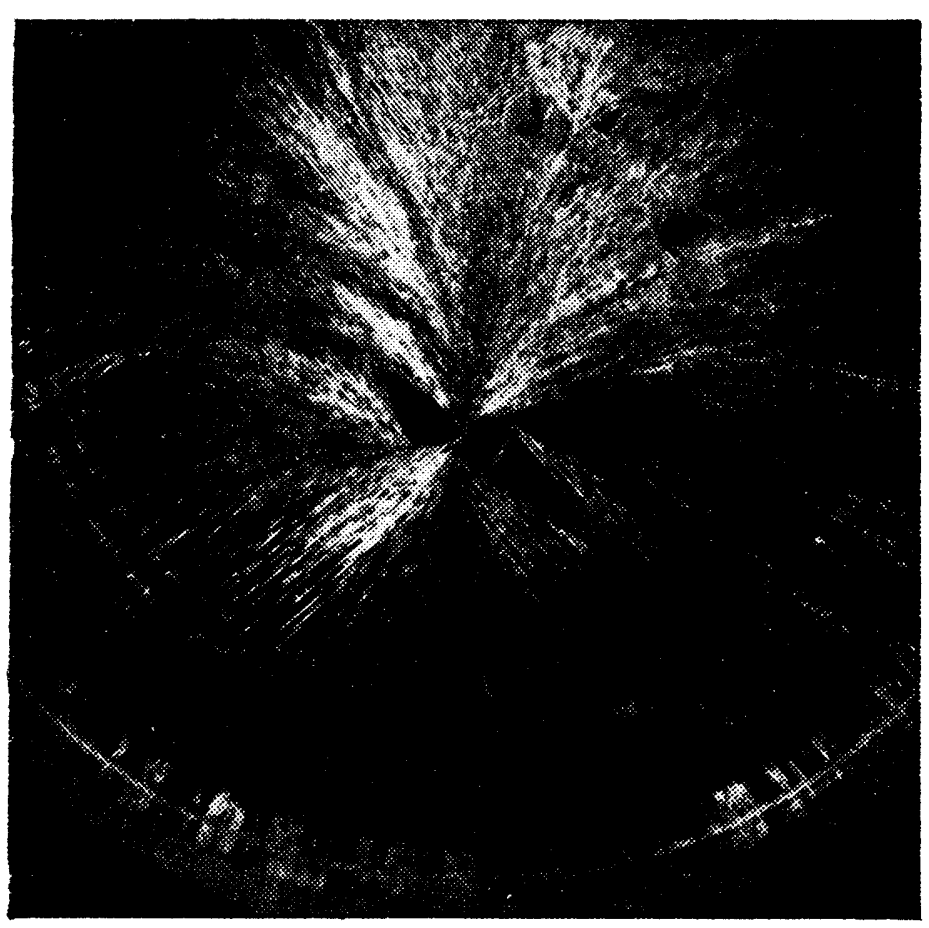

Fig. 1: extrato de flores, cultivar roxinho, $1,1 \mathrm{X}$

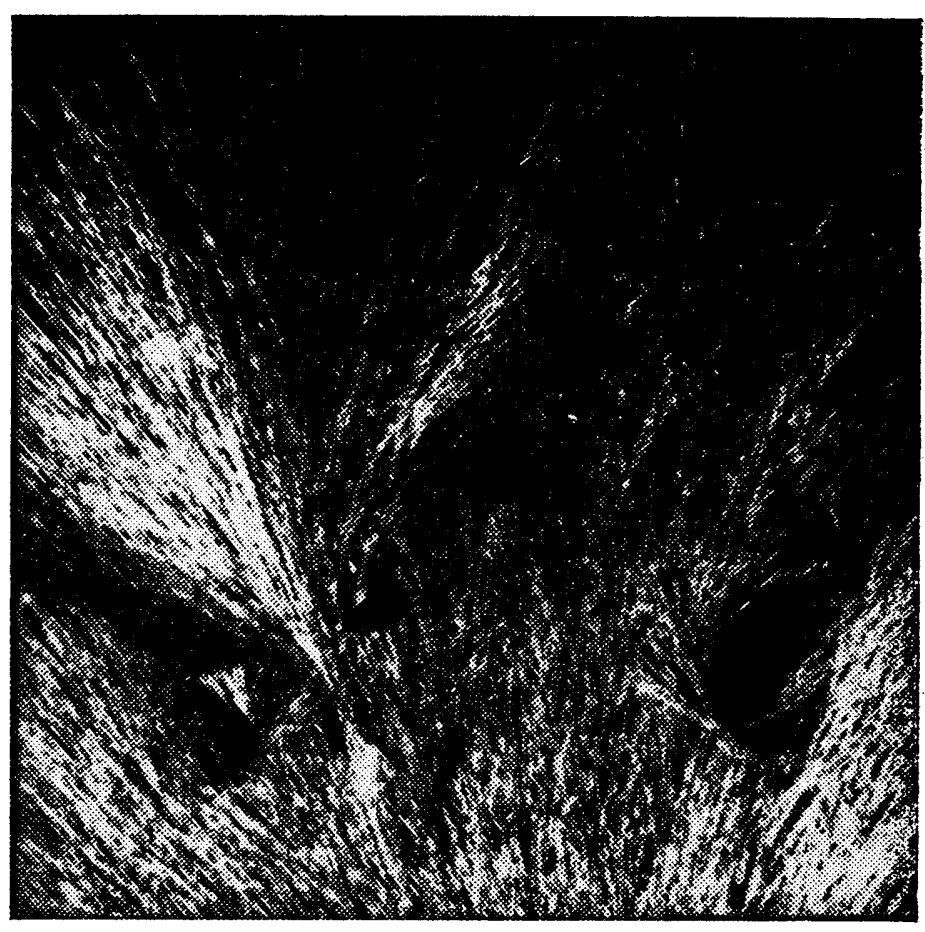

Fig. 2: extrato de flores, cultivar rexinho, $3 \mathrm{X}$

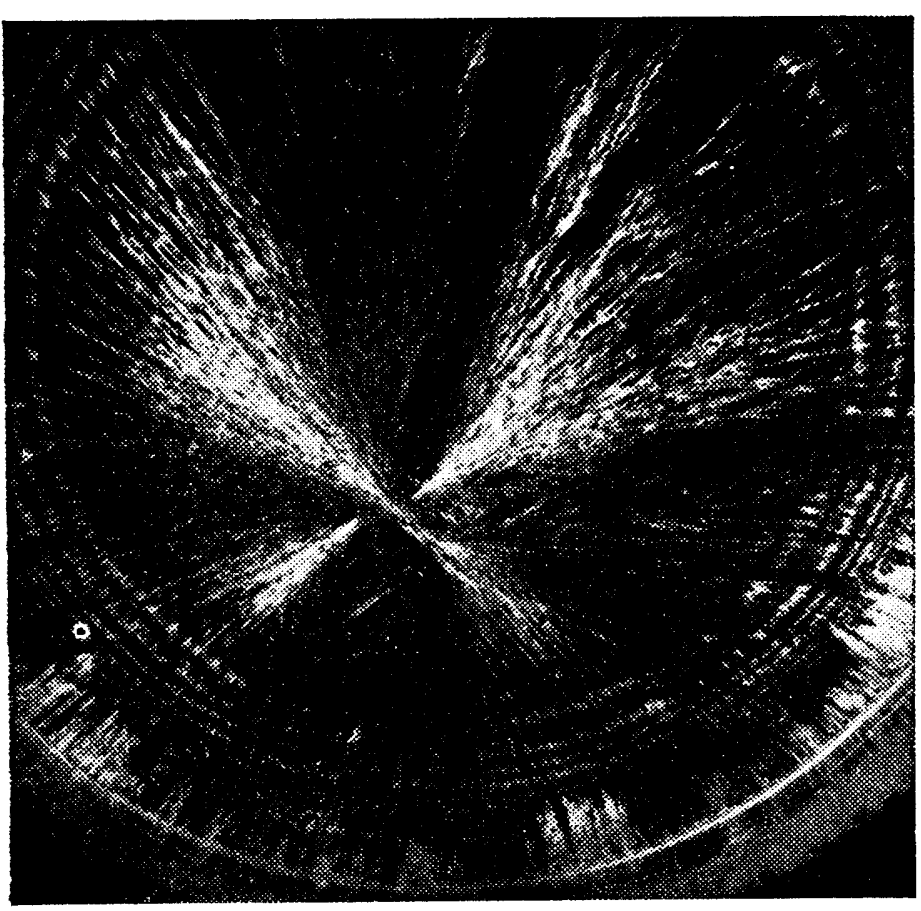

Fig. 3: extrato de flores, cultivar preto, $1,1 \mathrm{X}$

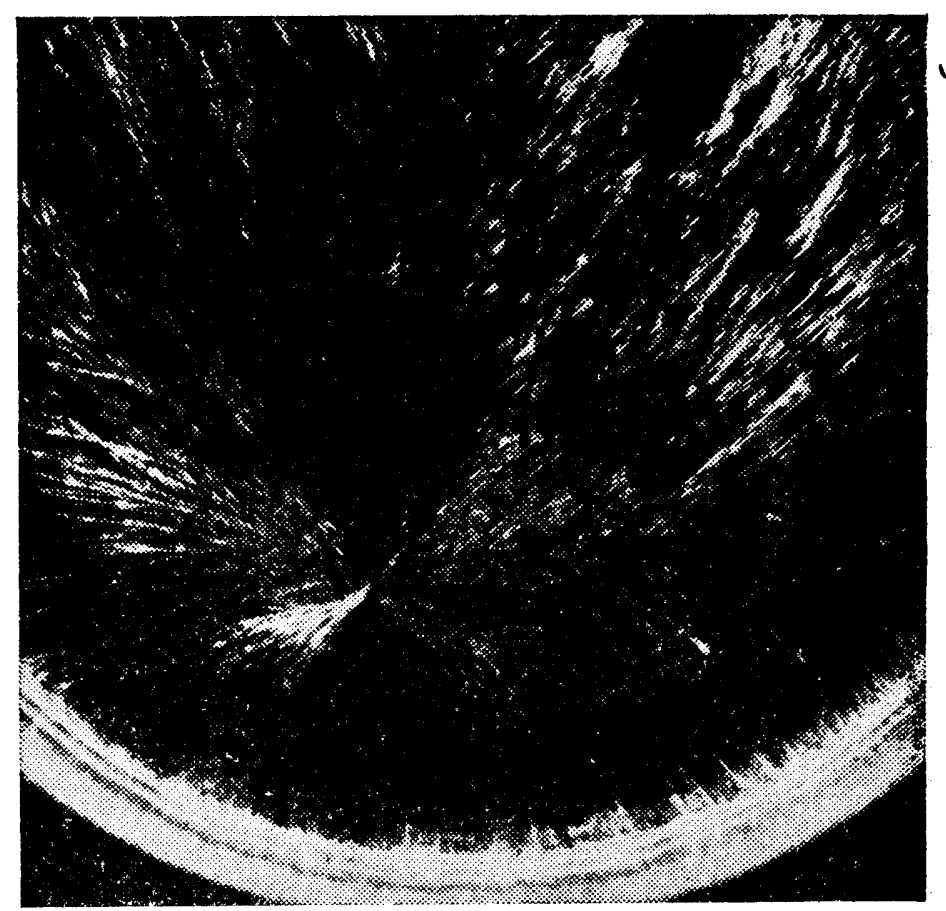

Fig. 4: extrato de flores, cultivar pintado, $1,1 \mathrm{X}$ 
Na concentração $0,025:$ : 0,5 , a comparação entre os modelos de roxinho e pintado confirmam que o de roxinho é melhor, permitindo distinção simples e segura entre os 2 cultivares. A concentração 0,025: 0,75 mostrou-se inadequada para os 2 cultivares, embora ainda fosse possível constatar diferenças.

Comparação dos modelos de cristalização de sementes - $\mathrm{O}$ modelo geral para sementes é muito característico e distingue-se facilmente do de outros orgãos. Os caracteres diferenciais entre variedades, no entanto, não são numerosos nem seguros. O mais evidente é a centragem que diferencia o cultivar preto, cujo modelo exibe também uma transição mais larga entre a borda e a cristalização central. Tendência para anéis concêntricos só se observa para pintado e cristalizações transversais só se constataram para roxinho.

\title{
CONCLUSÕES
}

1 - O método de cristalização do cloreto de cobre na presença de extratos aquosos de plantas mostra ter sensibilidade suficiente para permitir a distinção de variedades de feijoeiro através dos seus modelos de cristalização.

2 - Caracteres morfológicos diferenciais podem ser constatados para todos os orgãos estudados, com variações em função da idade da planta, embora não seja possível, ainda, estabelecer um caráter específico para cada variedade. As diferenças mais nítidas e constantes foram observadas nos modelos de cristalização de flores.

3 - Os resultados obtidos mostram que é conveniente que se pesquise a caracterização de variedades através de séries de cristalização simultânea, com delineamento específico para esse fim.

\section{SUMMARY}

\author{
VARIETIES DISTINCTION OF DRY BEANS (Phaseolus vulgaris L.) \\ THROUGH SENSITIVE CRYSTALLIZATION
}

The possibility of using plant varieties as crystallization pattern modifiers is studied. Crystallization models were obtained for roots, stems, leaves, flowers and seeds, of three varieties of dry beans obtained from nutritive solution. The concentration used mostly was $0,05: 0,5$. Comparison of the patterns showed that the sensitivity of the method is sufficient to warrant its employment in distinguishing varieties, especially when using flower extracts. 


\section{LITERATURA CITADA}

ABRAHÃO, I.O., 1965 - Cristalogênese do cloreto de cobre. Aplicação do método de de Pfeiffer ao feijoeiro (Phaseolus vulgaris L.). Tese de doutoramento apresentada à ESALQ, $134 \mathrm{pp}$.

AERAHÃO, I.O., 1970 - Aplicação do método de Pfeiffer a sementes de café (Coffea arabica L.). Anais da ESALQ, Piracicaba, vol. XXVII, 61-71.

ATRAHÃO, I.O., 1971 - Morfologia do cloreto de cobre na presença de extratos aquosos de feijoeiro (Phaseolus vulgaris L.). Anais da ESALQ, Piracicaba, vol. XXVIII, 199-216.

ABRAHÃO, I.O., 1975 - Cristalogênese do cloreto de cobre: efeito de extratos de senentes de feijoeiro (Phaseolus vulgaris L.). Anais da ESALQ, Piracicaba, vol. XXXII, n. ${ }^{\circ} 62$.

KRƯGER, H., 1949 - Tagezeiten - Rhytmen bei Pflanzen. Weleda - Nachrichten 22, 8-11.

KRÜGER, H., 1950 - Kupferchlorid - Kristallisationen, ein Reagens auf Gestaltungsskräfte des Lebendigen. Weleda - Schriftenreie. Heft 1, 5-30.

MORRIS, D.L. e MORRIS, C.T., 1938 - Specific effects of certain tissue extracts on the crystallization pattern of cupric chloride. Journal of Physical Chemistry 43, 623-629.

MORRIS, D.L. e MORRIS, C.T., 1939 - Glycogen in the seed of Zea mays (variety golden bantam). The Journal of Biological Chemistry. Baltimore, USA, vol. 130, $535-544$.

MORRIS, D.L. e MORRIS, C.T., 1940 - The modification of cupric choloride crystallization patterns by trace of proteins. The Journal of Biological Chemistry. Baltimore, USA, vol. $141,515-521$.

PFEIFFER, E., 1930 - Kristalle. Orient-Ocidente Verlag, Stuttgart, Alemanha, 81 pp.

PFEIFFER, E., 1940 - Sensitive Crystallization. Chemical Products and the Chemical News. Londres, n. ${ }^{\circ} 3,21-25$.

SELAWRY, A. e SELAWRY, O., 1957 - Die Kupferchloride Kristallisation in Naturwissenschaft und Medicin. Gustav Fischer Verlag, Stuttgart, Alemanha, 232 pp. 
